\title{
Пассивная гармоническая синхронизация мод в эрбиевом волоконном лазере
}

\author{
А.И. Трикшев ${ }^{1, *}$, В.А. Камынин ${ }^{1}$, В.Б. Цветков ${ }^{1,2}$ \\ ${ }^{1}$ Институт общей физики им. А.М. Прохорова РАН, Москва \\ ${ }^{2}$ Национальный исследовательский ядерный университет "МИФИ", г. Москва \\ *E-mail: trikshevgpi@gmail.com
}

DOI:10.31868/RFL2018.156-157

В последние годы во многих областях науки и технологии находят применение лазеры ультракоротких импульсов (УКИ) высокой частоты, благодаря таким качествам, как высокая оптическая эффективность, широкий диапазон рабочих параметров, масштабируемость. В оптической метрологии и молекулярной спектроскопии высокостабильные лазерные системы УКИ позволяют получать данные с улучшенным отношением сигнал-шум, таким образом уменьшая время измерения. Такие системы подходят и для систем навигации, где требуются высокоточные стандарты частоты, и для системы высокоскоростной передачи данных. Особое место такие источники занимают в радиофотонике. Данное направление является мощным стимулом для развития целых разделов фотоники: высокостабильных непрерывных и импульсных лазеров, в том числе фемтосекундных, фотоприемников, волоконных фильтров, фотонных аналого-цифровых преобразователей для частот более 10 ГГц.

Существует несколько способов создания таких лазерных систем: использование твердотельных или полупроводниковых лазеров с коротким резонатором [1], использование микрорезонаторов [2], использование лазерных систем с гармонической синхронизацией мод. Под гармонической синхронизацией мод понимается такой режим работы лазера, при котором в резонаторе одновременно существуют несколько импульсов с равными временными интервалами.

Синхронизация мод может быть получена несколькими способами:

- использование насыщающихся поглотителей (SESAM или углеродные нанотрубки) [3],

- использование эффекта нелинейного вращения поляризации (NPR) [4],

- использование нелинейных волоконных зеркал [5].

В нашей работе продемонстрирован импульсный кольцевой волоконный лазер, работающий в режиме пассивной гармонической синхронизации мод на основе эффекта нелинейного вращения плоскости поляризации. В качестве активной среды использовалось эрбиевое волокно длиной 1 метр. Накачка осуществлялась лазерным диодом с длиной волны 1461 нм. Мощность диода накачки варьировалась в диапазоне от 30 до 180 мВт. Общая длина резонатора, с учетом линии задержки на SM-волокне, составляла 2.4 метра, что обеспечивало частоту повторений импульсов на основной гармонике в 84 МГц. Гармоническая синхронизация достигалась путём тщательной настройки контроллеров поляризации и оптимизации мощности накачки.

На рисунках 1,2 показаны осциллограммы выходных импульсов и соответствующие автокорреляционные функций. Максимальная рабочая частота составляла 5,62 ГГц, что соответствовало 67-й гармонике. На рис. 2 представлены спектры выходного излучения. 

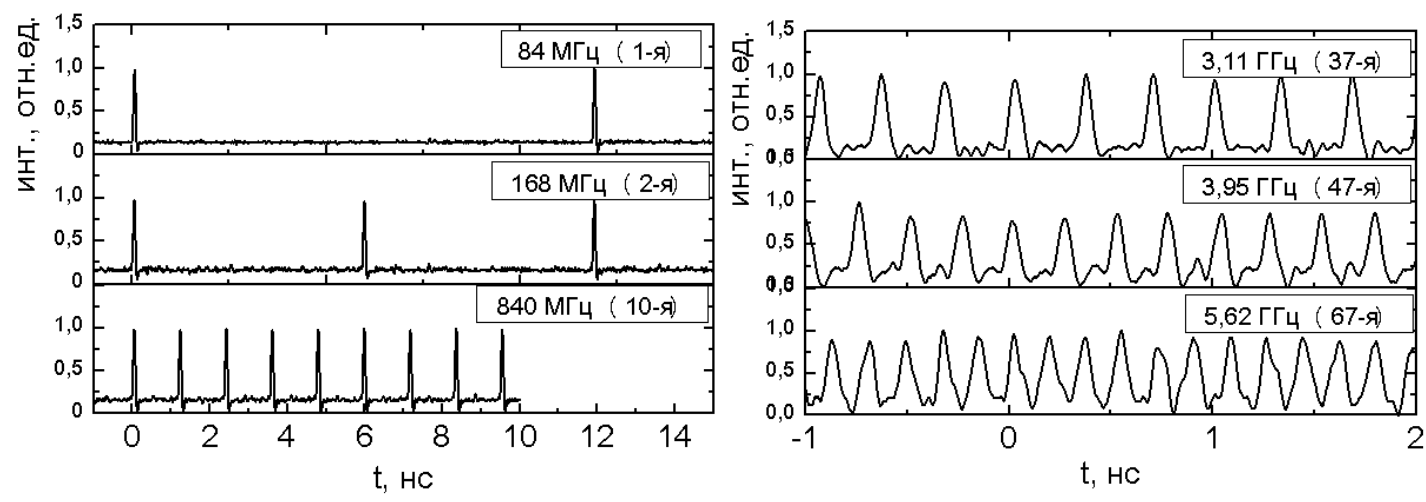

Рис. 1. Осциллограммы выходных импульсов.
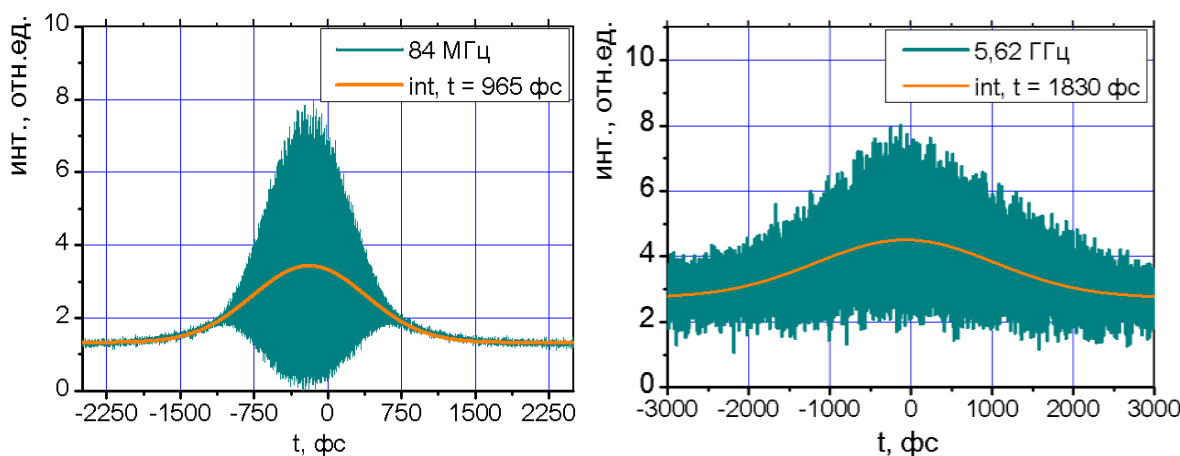

Рис. 2. Автокорреляционные функции выходного излучения на разных гармониках.

Эти режимы можно объединить в серии, которые характеризовались стабильной работой на одинаковых длинах волн. При этом была возможность перестройки лазера на разные гармоники в пределах одной серии. Длительность импульсов изменялась в диапазоне от 0.8 до 1.8 пс. Замечено, что при переходе на высокие гармоники длительность импульса увеличивалась, а ширина спектра генерации уменьшалась.

Работа выполнена при поддержке Президиума Российской Академии Наук в рамках программы фундаментальных исследований № I.7 «Актуальные проблемы фотоники, зондирование неоднородных сред и материалов».

\section{Литература}

[1] U. Bandelow, et al, Opt Quant Electron 38: 495 (2006)

[2] T.J. Kippenberg, et al, Science: 332 (6029), pp. 555-559 (2011)

[3] J. Sotor, et al, Laser Phys. Lett., 11,055102. (2014)

[4] J. Peng, et al, J. Lightw. Technol., 31, 3009-3014 (2013)

[5] H.R. Chen, et al, Opt. Lett. 38, 845-847 (2013) 